\title{
GENETIC ENGINEERING AS A TOOL FOR MODIFICATION OF SEED STORAGE PROTEINS AND IMPROVEMENT OF NUTRITIONAL VALUE OF CEREAL GRAIN
}

(review)

\section{L.A. EL'KONIN, I.V. DOMANINA, Yu.V. ITAL'YANSKAYA}

«So modern bread wheat is the result of crossing three species barriers, a kind of natural genetic engineering»

(Norman Ernest Borlaug, Nobel laureate)

Agricultural Research Institute for South-East Region, Federal Agency of Scientific Organizations, 7, ul. Tulaikova, Saratov, 410010 Russia, e-mail lelkonin@gmail.com

Received August 25, 2015

doi: 10.15389/agrobiology.2016.1.17eng

\section{Abstract}

In recent years, genetic engineering has become an effective tool for the genetic improvement of cultivated plants including changes in the composition grain storage proteins of cereal crops that are the main source of nutrition for humans. The review describes the approaches used in these studies: the introduction of genetic constructs (i) providing the synthesis of proteins that are absent in recipient cultivars; (ii) inducing RNA-silencing of genes encoding proteins with low nutritional value, (iii) regulating the pool of amino acids in the endosperm. The studies are referred, which reported on the introduction of additional genes of high molecular weight glutenins (1Dx5,1Ax1,1Bx17,1By18,1Dy10 and others) into the genomes of different lines and cultivars of wheat. In these studies, the transgenic lines with increased dough strength and elasticity were obtained. In addition to the practical importance, these studies allow understanding the role of individual genes of high and low molecular weight glutenins in the formation of wheat flour quality traits. The examples of marker-free transgenic wheat lines expressing $1 D y 10$ and $1 B \times 14$ genes, as well as transfer of high molecular weight glutenin genes into the genomes of other cereals (rye, corn, sorghum) are given. The possibilities of using the RNAi technology to obtain new information about the mechanisms of development of protein bodies, vitreous endosperm formation, and the role of different classes of prolamins and glutenins in the technological properties of flour and dough are discussed. The examples of the creation of transgenic maize with improved nutritional value via RNA-silencing of prolamin genes, transgenic sorghum with improved protein digestibility (obtained by silencing gene of the $\gamma$-kafirin, the protein that forms outer layer of the protein bodies, resistant to pepsin digestion), transgenic wheat with suppression of gliadin synthesis, which flour has a low toxicity to humans with celiac disease, forced to comply gluten-free diet, are given. An example of natural RNA-silencing is given Partivularly, in the rice mutant with reduced level of glutelin, a deletion between the two coding sequences, one of which has an inverted orientation has been detected in the Lgcl locus. The genetic engineering approaches to increase the lysine content are described, e.g. introduction of genes that enhance its synthesis, such as dihydrodipicolinate synthase (DHPS) insensitive to feedback inhibition and aspartate kinase; suppression of $z l k r / s d h$ gene regulating its catabolism; introduction of genes that control the synthesis of proteins with high lysine content (histones and other lysine-rich proteins). The prospects of using genetic engineering methods to create varieties with improved nutritional value are associated with the use of marker-free technologies, increasing accuracy of insertion of genetic constructs, using the methods of genome editing by artificially engineered nucleases.

Keywords: transgenic plants, RNAi, prolamins, protein bodies, endosperm, cereal crops.

The studies over the past 20 years have convincingly demonstrated that genetic engineering becomes a highly effective tool of the genetic improvement of cultivated plants. The reality is that genetic engineering has become one of the method for breeding different crops, which allowed to create a significant number of cultivars and lines, resistant to biotic and abiotic stresses, with im- 
proved quality of final products, increased photosynthetic and nutrient-use efficiency (https: //www.isaaa.org/gmapprovaldatabase/).

Among the various methods of genetic engineering, Agrobacteriummediated plant transformation is considered the most effective and least costly approach in obtaining transgenic plants. For a long time, this technique has been poorly used for cereal crops, for which the expensive ballistic transformation served as the only actual way of transgenesis. However, improvement of methods for regenerating cereal plants in tissue culture and the development of various protocols for Agrobacterium-mediated transformation [1, 2] greatly facilitated the production of transgenic plants in cereals, significantly expanding the possibilities of using genetic engineering in plant breeding of such an important group of crops.

Among the most promising areas of genetic engineering is the creation of transgenic plants, which are improved nutritionally via the changed composition of grain storage proteins. These investigations are particularly relevant for cereals being the main source of food and feed protein. It is known that up to $50 \%$ protein (or up to $70 \%$ in developing countries) and up to $65 \%$ of calories humans receive from cereals, in which the storage proteins account for up to $80 \%$ of the total protein content in the mature seed [3-5].

The article provides an overview of studies on the production of transgenic cereal crops with modified composition of storage proteins. We investigated the possibilities of using these plants for the study of protein bodies and the formation of endosperm, as well as creating lines with a higher nutritional value.

Fractions of grain storage proteins in cereals. According to the widely used classification by T.B. Osborne, storage proteins are divided into albumin (water-soluble), globulin (salt-soluble), prolamine (spirit-soluble), and glutenin (alkali-soluble) fractions [6].

In bread wheat (Triticum aestivum L.), the major cereal crop, storage proteins are represented by glutenins (50\% of the total pool of endosperm proteins) and gliadins (30\%). Glutenins are polymer complexes, which define elasticity of flour, composed of subunits with high and low molecular weight (HMW and LMW, respectively). Bread wheat contains closely linked pairs of genes that encode X- and Y-types of subunits, forming HMW proteins, and are located on the long arm of chromosomes 1A, 1B and 1D. Gliadins consist of $\alpha-, \gamma-$ and $\omega-$ fractions with different electrophoretic mobility [7]. Gliadins are regulated by closely linked gene clusters, called blocks, which are located in the chromosomes 1 and 6 [4, 8].

Prolamins are the main storage proteins in corn Zea mays L. and sorghum Sorghum bicolor (L.) Moench. Fractions of maize prolamin (zeins) are $\alpha-$ $(19 \mathrm{kDa}$ and $22 \mathrm{kDa}), \beta-(15 \mathrm{kDa}), \gamma-(50 \mathrm{kDa}, 27 \mathrm{kDa}, 16 \mathrm{kDa})$ and $\delta-(18$ $\mathrm{kDa}$ and $10 \mathrm{kDa}$ ) zeins, whereas $\alpha$-zeins in the endosperm of maize kernels account for up to $70 \%$ of the total protein pool $[5,6]$. Zeins contain small amounts of valuable amino acids such as lysine, threonine, tryptophan, and therefore having a low nutritional value. In 1960s, the opaque-2 (o2) and floury2 (fl2) corn mutants were obtained with a reduced content of $\alpha$-zein, in the endosperm of which a significant amount of non-zein proteins rich in lysine was accumulated, and an increased content of free lysine and tryptophan was also observed [6]. The kernels of these mutants, however, contained no vitreous endosperm, and that increased the fragility of the kernels, their susceptibility to infection with fungal microflora, and, ultimately, hindered the commercial use of such mutants. Later, recombinants with vitreous endosperm and a high content of lysine (QPM, Quality Protein Maize) have been obtained. In these, a compensatory synthesis of non-zein proteins rich in lysine occurred in the kernels, 
along with an increase in the $\gamma$-zein content $[6,9]$.

Similarly to corn, sorghum prolamine fractions (kafirins) were designated as $\alpha-(25 \mathrm{kDa}$ and $23 \mathrm{kDa}), \beta-(18.7 \mathrm{kDa})$ and $\gamma$-kafirins $(28 \mathrm{kDa})$ [10-12]. Data on molecular weight of $\gamma$-kafirin disagreed in different studies, $28 \mathrm{kDa}$ [10] or $20 \mathrm{kDa}$ [13]. According to the last published classification, sorghum kafirins are represented with six proteins, such as $\alpha$-kafirin $1(25 \mathrm{kDa})$, $\alpha$-kafirin 2 (22 kDa), $\beta$-kafirin (19 kDa), $\gamma$-kafirin 1 (27 kDa), $\gamma$-kafirin 2 (50 kDa), $\delta$-kafirins $(18 \mathrm{kDa})$, with the $\alpha$-kafirin fraction amounting up to $80 \%$ of the total amount of kafirin proteins [14].

Prolamins synthesized in endosperm cells are deposited in highly specialized organelles, i.e. protein bodies with a well-ordered structure [5]. Protein bodies are formed as the endoplasmic reticulum vesicles. First, $\gamma$ - and $\beta$ prolamins accumulate in these vesicles, and then $\alpha$ - and $\delta$-prolamins begin to accumulate, while $\gamma$ - and $\beta$-prolamins are pushed away to the outer layers. Such an organization of protein bodies is considered as one of the major causes of a lower nutritional value of sorghum grains as $\gamma$-kafirin occupying a peripheral position is highly resistant to proteolytic degradation, thereby preventing the digestion of the major storage proteins, i.e. $\alpha$-kafirins $[15,16]$.

Storage proteins in rice (Oryza sativa L.) are represented by prolamins and glutelins. Prolamins are divided into three subclasses: $10 \mathrm{kDa}, 13 \mathrm{kDa}$ (13a-1, 13a-2, 13b-1 and 13b-2) and $16 \mathrm{kDa}$. Prolamins $13 \mathrm{a}-1$ and $13 \mathrm{a}-2$ belong to proteins rich in cysteine, while $13 b-1$ and $13 b-2$ are cysteine-deficient. Genes encoding prolamine $13 \mathrm{~b}-2$ exist in 18 copies, genes of the other prolamins have a lower copy number ( 2 to 4 copies per genome) [17].

Prolamins and glutelins in the endosperm of rice kernels are deposited in the protein bodies. Protein bodies containing prolamine have a spherical shape, 1-2 microns in size and an inner structure with concentric circles of different electron density; protein bodies containing glutelin are irregular in shape, 3-4 microns in size and uniformly coloured [18, 19]. It has been established that prolamine $10 \mathrm{kDa}$ is located in the centre of the protein body, prolamins $13 \mathrm{a}$ and $16 \mathrm{kDa}$ are found in the middle layer, while prolamine 13b forms the surface layer and the lining between the inner layer and the middle layer of the protein body [17].

Transgenic plants with additional storage protein genes. Development of genetic transformation has opened the possibility of using genetic engineering techniques to modify the composition of storage proteins in cereal crops. To solve this problem, different approaches are used such as the introgression of genes regulating synthesis of storage proteins, which are absent in the recipient cultivars; the introgression of genetic constructs that induce RNA silencing of genes encoding proteins with a low nutritional value or reduce the degradation of other proteins by proteases; the introgression of genes regulating amino acid synthesis.

To date, the literature contains a considerable number of reports on the introduction of genes of various high molecular weight glutenins (1Dx5,1Ax1, $1 B x 17,1 B y 18,1 D y 10$, etc.) in the genomes of different lines and cultivars of bread wheat. The studies resulted in obtaining transgenic lines with improved quality of flour, increased dough rising potency and elasticity [20-24]. In addition to practical value, these works allow understanding the role of individual genes of high and low molecular weight glutenins in flour quality. Thus, a decline in the SDS-sedimentation index and flour strength was observed in transgenic bread wheat lines with enhanced expression of low molecular weight glutelin genes [24]. Simultaneous expression of three genes of HMW-GS, i.e. $1 A x 1$, $1 D \times 5$ and $1 D y 10$, increased the flour rising potency, with much more pronounced effect of gene $1 D y 10$ compared to $1 A x 1$ and $1 D x 5$ [25]. 
There have also been reports on durum wheat transgenic plants with genes $1 A x 1$ or $1 D_{x} 5$ encoding high molecular weight glutenins [26]. Among 10 transgenic lines which were obtained by the ballistic transformation of immature embryos from three cultivars and a line of Triticum turgidum L. var. durum, five ones demonstrated the expression of introduced transgenes. An analysis of the flour mixogram based on the grains from three transgenic lines has revealed the elevation of dough rising potency and stability, which indicates the possibility of using genetic transformation technique to improve the quality of durum wheat grain.

In a similar work done on other cultivars of durum wheat, the transgenic lines with bread wheat genes $1 D_{x} 5$ and $1 D y 10$ encoding high-molecular glutenins also were obtained [27]. However, it is notable that transgenes and a marker gene (bar) in one of the lines appeared to be located on different chromosomes, so as the segregation resulted in isolation of a markerless transgenic line expressing gene 1Dy10. The flour from obtained transgenic lines had improved kneading properties.

Durum wheat transgenic plants with genes encoding high molecular weight glutenins LMW-GS [28] have also been obtained, and as a result a transgenic line with enhanced flour strength was developed [29].

Taking into account the possible negative effects of the marker gene bar on human health, efforts have been undertaken to obtain markerless transgenic plants of bread wheat with extra storage protein genes [30]. In this study, PCR was used to select transgenic plants with the gene $1 B x 14$ encoding a high molecular glutenin subunit. Seven transformants (transformation frequency $0.28 \%$ ) have been identified among 1219 plants, with three of them demonstrating the transgene expression in the $\mathrm{T}_{1}$ generation.

Noteworthy experiments were reported in which high molecular glutenin genes were transferred into the genomes of other cereal crops. Thus, it has been reported about a transgenic line of rye (Secale cereale L.) with bread wheat glutenin genes Glu-1DX5 and Glu-1Dy10, which boasted 2- to 3-fold increase in the gluten content [31]. Transgenic plants of corn and sorghum with genes Glu$1 D X 5$ and $1 D y 10$ introduced in their genomes, respectively, have also been developed, and these genes showed specific expression in the endosperm [32, 33].

Using RNA interference to change the composition of storage proteins. The RNA interference technique is known to be based on destructing mRNA of the target genes via genetic constructs containing inverted repeated sequences of these genes' fragments. The mRNA transcribed from such structures forms a hairpin structure. The resulting double-stranded RNA molecule is exposed to destruction with subsequent formation of single-stranded fragments 21-25 bps long (short interfering RNA), which interact with mRNA of the target gene due to complementarity. As a result, there are new double-stranded RNA molecules that are also subject to destruction [34-36].

In recent years, RNA interference technology has been extensively used to improve the nutritional value of a number of cereals, particularly corn and sorghum, as well as to obtain new information about the mechanisms of protein bodies' formation, the endosperm structure, and the role of various classes of prolamins and glutenins in determining properties of flour and dough.

By means of ballistic transformation using a genetic construct, which contained the $\gamma$-gliadin gene fragment sequences in direct and reverse orientations, separated by the intron Ubil, seven transgenic plants with silencing of the $\gamma$-gliadin gene were obtained from two lines of the wheat cultivar Bobwhite [37]. Further on, the construction for RNA silencing was moved via crossings into the genomes of other three bread wheat cultivars that led to an increase in the number of high and low molecular weight glutenins and SDS sedimentation value as 
a result of silencing [38]. It is noteworthy that such an effect of silencing $\gamma$ gliadin gene was not found in the gene pool of the Bobwhite 208 cultivar.

Other experiments with the use of genetic constructs for RNA silencing of the genes of $\alpha$ - and $\omega$-gliadins revealed repression of the synthesis of all gliadin classes (up to $86.8 \%$ compared with that observed in the original non-transgenic plants) [8]. Abnormalities in the development of protein bodies which had an irregular shape have been identified in these lines, whereas repression of the synthesis of $\gamma$-gliadin alone did not change the shape of these structures. In lines carrying a genetic construct targeted at silencing genes of $\alpha$ - and $\omega$-gliadins, an increase in the content of globulins was seen. It was also reported the development of a transgenic wheat with silencing of the $\alpha$-gliadin gene, and this wheat was characterized by a high flour strength index and increased baking volume [39].

Transgenic wheat lines harbouring the genetic construct for silencing $\omega$ 5 -gliadin gene were obtained [40]. The content of $\omega$-5-gliadin in two lines was decreased by $80 \%$, while the synthesis of other gluten proteins was not altered. At the same time, two other lines showed both complete suppression of the $\omega-5$ gliadin synthesis and down-regulation of $\omega$-1,2-gliadins. Moreover, one of the lines also demonstrated the decreased synthesis of three proteins from the high molecular glutenins and one low molecular weight glutenin (s-type LMW-GS), and simultaneously increased content of two other low molecular weight glutenins (m-type LMW-GS) and several $\alpha$-gliadins. This study clearly demonstrates that the same construct for RNA silencing may cause different effects depending on the gene pool.

It should be noted that the flour of transgenic wheat lines with suppressed synthesis of gliadins is less toxic for people suffering from celiac disease and forced to keep a gluten-free diet. It has been showed that the gluten proteins in transgenic wheat lines with silencing of genes of $\alpha-\gamma$ - and $\omega$-gliadins may reduce the formation of epitopes (DQ2 and DQ8) [41] specifically associated with the celiac disease and recognized by $\mathrm{T}$-cells. Therefore, transgenic wheat with suppressed synthesis of gliadins may be used in food by people with celiac disease who are not able to consume products based on conventional wheat, rye and barley flour.

In corn, using genetic constructs harbouring inverted repeats of genes of $\alpha$-zeins (19 kDa and $22 \mathrm{kDa}$ ), transgenic lines with suppressed synthesis of these proteins were obtained [42, 43]. It was found that repression of the synthesis of zeins possessing a relatively low nutritional value leads to accumulation of other proteins with a higher nutritional value. Corn plants with gene silencing of $\alpha$ zeins were characterized by doubled content of essential amino acids tryptophan and lysine in the kernels.

These experiments have found that silencing gene of $\alpha$-zein with a molecular weight of $22 \mathrm{kDa}$ resulted in the formation of the floury endosperm. Such a modification in the type of endosperm was associated with abnormalities in the formation of the structure of protein bodies, namely the violation of embedding a $19 \mathrm{kDa} \alpha$-zein into the centre of a protein body, or a modification of its interaction with $\beta$ - and $\gamma$-zeins [42].

Later on, RNA interference of genes of various zein fractions in the QPM maize line with a vitreous endosperm allowed obtaining a variety of mutants with different variations in the protein body structure and types of endosperm [44, 45]. It has been demonstrated that silencing of the $\gamma$-zein gene plays an important role in the formation of the floury endosperm, which results in a modification of the protein body structure and a change of their relationship with the starchy granules [45]. 
A thorough study of various zein subclasses, using the RNA interference technique, has revealed their role in the formation of the vitreous endosperm and development of protein bodies in corn [46]. Thus, it was found that a $27 \mathrm{kDa} \gamma-$ zein is involved in the initiation of protein body formation. Other proteins belonging to the family of $\gamma$-zeins operate at the stage of protein body growth. Cosuppression of two $\alpha$-zeins (19 $\mathrm{kDa}$ and $22 \mathrm{kDa}$ ) significantly inhibits the outgrowth of protein bodies, but does not induce their morphological anomalies, which do arise from the reduction of a $22 \mathrm{kDa} \alpha$-zein alone. The simultaneous suppression of all zein classes leads to a decrease in the number of protein bodies, which at the same time retain their normal size and morphology.

A large number of experiments on the induction of RNA silencing of kafirins in sorghum was carried out by several research groups. The main purpose was to suppress the synthesis of a poorly digestible $\gamma$-kafirin and develop sorghum lines with improved nutritional value. RNA silencing was induced by genetic constructs containing inverted repeats of several genes of kafirins $(\delta 2, \gamma 1$, $\gamma 2$ or $\alpha 1, \delta 2, \gamma 1, \gamma 2$ ) separated with a sequence of ADH1 (aldehyde dehydrogenase 1) intron. These constructs were controlled by a promoter of the maize $\alpha$-zein $(19 \mathrm{kDa})$ gene [14, 47, 48]. In another study [33], for induction of $\gamma$ kafirin gene silencing, a genetic construct comprising the complete sequence of the $\gamma$-kafirin gene was used, controlled by the $\gamma$-kafirin promoter, with the gene sequence of the ribozyme (self-cleaving ribozyme) of tobacco ringspot virus as the terminator. $\alpha$-Kafirin silencing was induced by a construct consisting of the inverted repeats of the $\alpha$-kafirin separated with an intron sequence of the Arabidopsis gene encoding the D1 protein of spliceosome; the construct was controlled by the $\alpha$-kafirin promoter [33]. All research groups succeeded in obtaining transgenic lines of sorghum with a floury type of endosperm and improved pepsin digestibility of kafirins. Unfortunately, the floury endosperm is a disadvantage of these lines, since the absence of a vitreous layer increases the fragility of kernels and reduces their resistance to fungal microflora.

By means of transformation using the Agrobacterium strain GV3101, carrying a genetic construct pNRKAFSIL, to induce RNA silencing of $\gamma$-kafirin gene, we managed to obtain transgenic lines of sorghum with in vitro improved digestibility of grain storage proteins and a modified amino acid composition (i.e., increased relative lysine content) [49]. The construct pNRKAFSIL developed in the «Bioengineering» Centre of RAS (Moscow; authors N.B. Ravin and A.L. Rakitin) was a hairpin insert consisting of the $\gamma$-kafirin gene fragments in direct and reverse orientations, with an intron of the maize ubiquitin gene located between them; the construct was controlled by a constitutive $35 \mathrm{~S}$ promoter of cauliflower mosaic virus (CaMV).

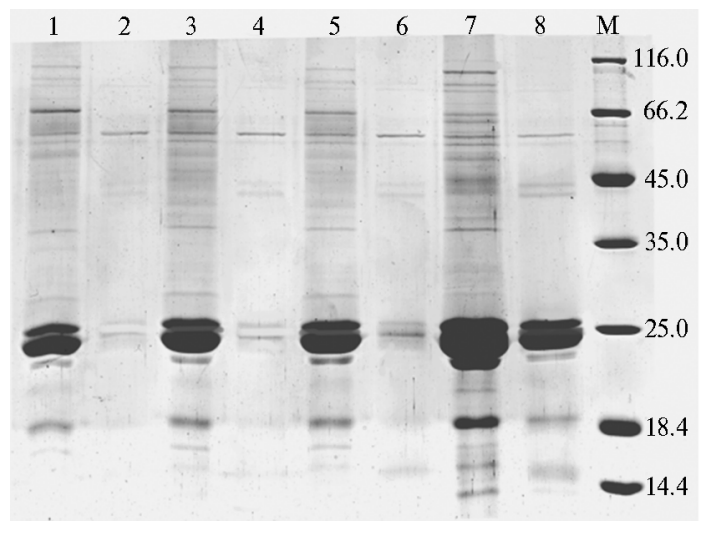

Fig. 1. Electrophoretic protein spectra of kernels from three transgenic plants of sorghum Sorghum bicolor (L.) Moench from $\mathrm{T}_{3}$ generation carrying a genetic construct for the $\gamma$-kafirin gene silencing (lines 1 to 6 ) and a control plant of the original nontransgenic line of Zheltozernoe 10 cultivar (lines 7, 8 ), pre-treatment (lines 1, 3, 5, 7) and after treatment (lines 2, 4, 6, 8) with pepsin. $M(\mathrm{kDa})$ is a molecular weight marker SM0431 (Thermo Scientific, Lithuania).

In vitro digestibility of proteins showed that in the transgenic 
plants the flour is characterized by higher values compared to the original sorghum line (Zheltozernoe 10 cultivar) (Fig. 1). In some transgenic plants, the level of proteins that were not digested by pepsin was 4.7 times lower, and amount of the undigested monomers of kafirins was 17.5-fold lower than that in the original line. However, digestibility (total score of the protein cleavage) has reached 90-92\% compared to that in the control untreated with pepsin, whereas the score in the original non-transgenic line was 60-61 \% [49]. Increased digestibility was observed in plants from different generations $\left(T_{1}-T_{3}\right)$ thus being inherited.

It is noteworthy that we obtained both plants with a floury type of endosperm and forms with a vitreous or modified endosperm type, which combined high digestibility score of kafirins with the presence of a vitreous layer in the endosperm (Fig. 2). The obtained transgenic plants are of great interest for the breeders as the vitreous layer is required to protect kernels from pathogens and mechanical damage.
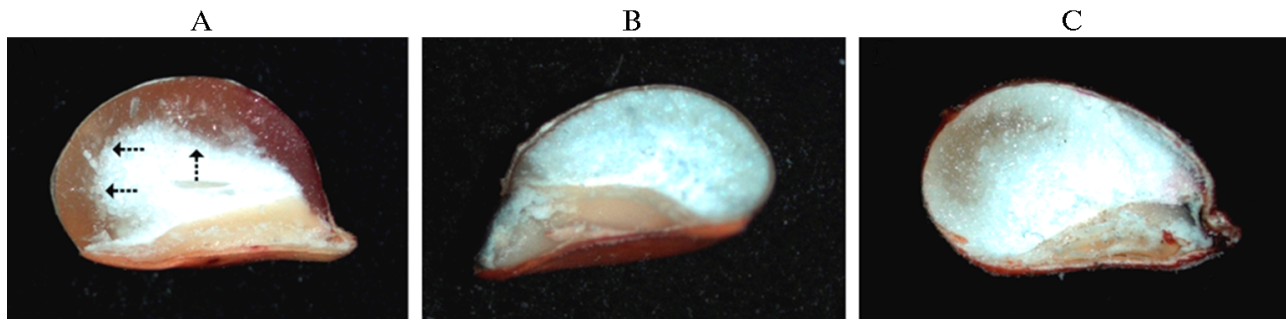

Fig. 2. Texture of endosperm in transgenic plants of sorghum Sorghum bicolor (L.) Moench containing a genetic construct for the $\gamma$-kafirin gene silencing: A - a kernel of the original nontransgenic line of Zheltozernoe 10 cultivar with a thick layer of vitreous endosperm (boundaries are marked with arrows); B - a kernel of a transgenic plant with the floury endosperm; C - a kernel of a transgenic plant with a modified type of the endosperm, where floury endosperm contains fragments of vitreous endosperm (StereoDiscovery V12, Carl Zeiss, Germany). Zoom by $\times 20.5$.

It should be noted that the structure of the protein bodies, which determines the digestibility and nutritional value of the sorghum grain, has been changed in the transgenic lines with the $\alpha$-kafirin gene silencing. Protein bodies in the endosperm of conventional sorghum line plants have a regular rounded shape, while the shape of these structures in the transgenic lines or mutants with high digestibility is irregular, with protrusions and grooves on their surfaces [14, 50]. At the same time, the $\gamma$-kafirin silencing has not changed the form of protein bodies [33, 47].

The RNA interference technique was used to study the mechanism of the formation and structure of protein bodies in rice. Using a genetic construct for silencing the gene of one of the prolamins, CysR10 (a $10 \mathrm{kDa}$ prolamine rich in cysteine), it was shown that this protein is a constituent part of the prolamine-containing protein bodies. In a line with RNA silencing, protein bodies lost their characteristic spherical configuration [51].

Changes in the shape and size of prolamine-containing protein bodies have been observed in transgenic rice plants with the gene silencing of a $13 \mathrm{kDa}$ prolamine [52]. In these transgenic plants, protein bodies were smaller and deprived of their characteristic lamellar structure. Moreover, it has been observed an elevation in the content of other proteins (a $10 \mathrm{kDa}$ prolamine, glutelins, chaperone) and free lysine that increased the nutritional value of the grain. It has also been showed that gene silencing of a $13 \mathrm{kDa}$ prolamine increases the total lysine content up to $56 \%$ as a result of a compensatory rise in the synthesis of lysine-rich glutelins, globulins and chaperones [53].

Of interest, there has been identified a natural mutation Lgcl (low glute- 
lin content) in rice, which reduces the amount of glutelin in kernels, probably by means of RNA interference. In the $L g c 1$ locus, a deletion was detected between two sequences of the glutelin gene, one of which had a reverse orientation. Such a structural organization of the locus during its transcription may result in the formation of a double-stranded RNA molecule, i.e. of the RNA silencing inductor [54]. Thus, the $\mathrm{Lgcl}_{\mathrm{C}} \mathrm{\text {mutation}}$ is a good example of the naturally occurring RNA silencing, and one of the arguments in favour of genetic engineering using the processes taking place in nature and occurring without human intervention.

Changes in the content of essential amino acids. Genetic engineering techniques are quite promising for enrichment of cereal grain with essential amino acids, i.e. lysine, tryptophan, methionine. By using endospermspecific promoters, expression of the desired genes may be provided exactly in the kernels, rather than in somatic tissues where the increased content of the mentioned amino acids may lead to developmental abnormalities [55]. However, to date, successful results in changing amino acid composition of cereal grains by genetic engineering were obtained only for lysine. To increase the content of this amino acid, various genetic engineering approaches have been used, i.e. the introduction of genes enhancing its synthesis; suppression of genes regulating the catabolism of lysine; inhibition of synthesis of proteins with a low content of lysine, which results in the initiation of lysine-rich protein synthesis in the endosperm; the introduction of genes that regulate the synthesis of proteins rich in lysine.

Lysine biosynthesis is triggered by dihydro dipicolinate synthase enzyme (DHDPS, KF 4.2.1.52). Its special feature is the response to inhibition by the end-product, which allows maintaining the concentration of lysine in the plant cells at a steady level [55]. However, a modified enzyme DHFPS called CordapA, non-responsive to inhibition by the end-product, was isolated from bacteria Corynebacterium glutamicum [56]. By means of Agrobacterium-mediated transformation, a transgenic maize line M27908 harbouring the CordapA gene was derived, where the content of free lysine increased more than 50-fold [57]. The crossing of the maize lines with RNA silencing of the $\alpha$-zein $(19 \mathrm{kDa})$ gene with the M27908 line carrying the gene CordapA allowed to obtain $\mathrm{F}_{1}$ hybrids, in which the total content of lysine in the kernels increased up to 6.9-8.5\% of the total amino acid content (vs $3.3 \%$ to $3.4 \%$ in the control) [57]. Therefore, a combination of two approaches (inhibition of lysine-deficient protein synthesis and the introduction of a gene that enhances the synthesis of this amino acid) allowed developing the hybrid maize with doubled lysine content in the kernel.

The catabolism of lysine is controlled by two enzymes, i.e. by lysine: $\alpha-$ ketoglutarate reductase (LKR, KF 1.4.3.2, EC 1.5.1.8) and saccharopine dehydrogenase (SDH, EC 1.5.1.9), which are products of a single gene $1 \mathrm{kr} / \mathrm{sdh}$ [5]. Using a genetic construct inducing RNA silencing of the $z l k r / s d h$ gene, transgenic plants were obtained in maize, which boasted a 20 -fold elevation in the lysine content compared to non-transgenic controls [58]. Subsequently, using a shared cassette which contained the CordapA gene enhancing the biosynthesis of lysine, and a genetic construct which induces RNA silencing of the $z l k r / s d h$ gene and thereby reduces the catabolism of lysine, there have been obtained transgenic corn plants with a 40-fold increase in this amino acid level in kernels [59].

It has been reported the development of transgenic rice plants with genes enhancing the synthesis of lysine, which encode an unresponsive to inhibition by lysine aspartate kinase (EC 2.7.2.4, EC 2.7.2.4) and dihydro dipicolinate synthase (EC 4.2.1.52), and constructs that induce RNA interference of the $1 \mathrm{kr} / \mathrm{sdh}$ 
gene, which controls the catabolism of lysine [60]. There has been recorded a 60 -fold increase in free lysine content in the seeds and a 12 -fold increase in the leaves of these plants. Any significant alteration in the plant development and seed germination was not shown.

As mentioned above, another way to enrich the kernels of corn and sorghum with lysine and tryptophan is to inhibit the synthesis of zeins, which contain low amount of these amino acids. The resulting compensatory effect in the kernels provides enhanced synthesis of non-zein proteins, which are richer in lysine and tryptophan [61]. A similar process was observed in transgenic sorghum lines with suppressed synthesis of kafirins and resulting enhanced synthesis of non-kafirin proteins in the kernels [33, 47].

In recent years, an approach based on the introduction of genes that regulate the synthesis of proteins rich in lysine has been used to develop lines of cereals with a high content of lysine. However, to provide the expression of such genes in the endosperm, the genetic construct includes the endosperm-specific promoter and, in some cases, a signal sequence directing the synthesized protein into the protein bodies. Transgenic rice plants were obtained just this way, with enhanced expression of genes encoding the synthesis of high lysine histones RLRH1 and RLRH2 in the seeds. Transgene transcription was ensured by the promoter of the rice glutelin 1 gene. The lysine content in the obtained transgenic plants has increased by $35 \%$ [62]. In another study, the wild potato (Solanum berthaultii) gene $s b 401$ encoding a lysine-rich protein of pollen cytoskeleton was inserted into the corn genome. As a result, the lysine content increased in the progeny of different transgenic plants by $16.1 \%$ to $54.8 \%$ as compared to the original non-transgenic line, and the total protein content increased by $11.6 \%$ to $39.0 \%$; moreover, increased amount of lysine and protein was consistently inherited in six generations [63]. In another study, in transgenic plants of corn with a cotton gene (Gossipium hirsutum L.) GhLRP regulating the synthesis of lysinerich protein the lysine content increased by $65 \%$ compared to a non-transgenic one [64]. It should be noted that the potential allergenic potency of these proteins had been eliminated before the work started, by means of test for homology with known allergenic sequences.

When discussing the prospects of practical application of genetic engineering techniques to create cultivars of cereal crops with improved nutritional value of the grain, it should be noted that the first transgenic corn cultivar LY038 with a higher lysine content was marketed in 2005 [55]. Negative public opinion and concerns about possible harmful effects of genetically modified foods on human health and the environment remain an obstacle to a wider distribution of transgenic cultivars. However, it is obvious that, with improvements of the methods for producing transgenic plants (e.g. using markerless technologies) [65, 66], enhancements in the accuracy of insertion of genetic constructs [67], and application of genome editing methods using artificially engineered nucleases [68], the number of transgenic cultivars of cereals improved on the targeted characteristics (in particular, the nutritional value) will be increasing as these experiments use DNA sequences encoding the beneficial and safe for humans products, with genetic engineering techniques of breeding based on naturally occurring processes.

Thus, the use of genetic engineering methods opens up great opportunities for the modification of the grain storage protein composition in cereals. These exploratory research studies are critical for solving theoretical problems associated with understanding endosperm development and mechanisms of the synthesis and accumulation of essential nutrients, i.e. protein and starch, in ontogeny. In addition, they have a direct practical way, because they allow 


\section{REFERE N C ES}

1. Hiei Y., Ishida Y., Ko mari T. Progress of cereal transformation technology mediated by Agrobacterium tumefaciens. Front. Plant Sci., 2014, 5: 628 (doi: 10.3389/fpls.2014.00628).

2. S park s C.A., D o h e rty A., J o n e s H.D. Genetic transformation of wheat via Agrobacterium-mediated DNA delivery. Methods Mol. Biol., 2014, 1099: 235-250 (doi: 10.1007/978-162703-715-0_19).

3. Godwin I.D., Willi a ms S.B., Pandit P.S., La id law H.K.C. Multifunctional grains for the future: genetic engineering for enhanced and novel cereal quality. In Vitro Cell \& Dev. Biol.-Plant, 2009, 45(3): 383-399 (doi: 10.1007/s11627-008-9175-5).

4. Shewry P.R., H alford N.G. Cereal seed storage proteins: structures, properties and role in grain utilization. J. Exp. Botany, 2002, 53(370): 947-958 (doi: 10.1093/jexbot/53.370.947).

5. Gibbon B.C., La rkins B.A. Molecular genetic approaches to developing quality protein maize. Trends in Genetics, 2005, 21(4): 227-233 (doi: 10.1016/j.tig.2005.02.009).

6. Holding D.R. Recent advances in the study of prolamin storage protein organization and function. Plant Sci., 2014, 5: 276 (doi: 10.3389/fpls.2014.00276).

7. Metakovsky E.V., Novoselsk y a A.Y., Sozinov A.A. Genetic analysis of gliadin components in winter wheat using two-dimensional polyacrylamide gel electrophoresis. Theor. Appl. Genet., 1984, 69: 31-37.

8. Gil- H u manes J., P ist on F., Shewry P.R., Tosi P., B a r ro F. Suppression of gliadins results in altered protein body morphology in wheat. J. Exp. Bot., 2011, 62(12): 42034213 (doi: 10.1093/jxb/err119).

9. Prasanna B.M., Vasal S.K., Kassahun B., Singh N.N. Quality protein maize. Curr. Sci., 2001, 81: 1308-1319.

10. Shull J.M., Watterson J.J., Kirle is A.W. Proposed nomenclature for the alcohol soluble proteins (kafirins) of Sorghum bicolor (L. Moench) based on molecular weight, solubility, and structure. J. Agric. Food Chem., 1991, 39(1): 83-87.

11. B elt o n P.S., D elgadillo I., Halford N.G., S h ew ry P.R. Kafirin structure and functionality. J. Cereal Sci., 2006, 44: 272-286 (doi: 10.1016/j.jcs.2006.05.004).

12. De Mesa-Stonestreet N.J., Alavi S., B e a n S.R. Sorghum proteins: the concentration, isolation, modification, and food applications of kafirins. J. Food Sci., 2010, 75: 90-104 (doi: 10.1111/j.1750-3841.2010.01623.x).

13. Wo ng J.H., Marx D.B., Wils o n J.D., Buchanan B.B., Le maux P.G., Peders e $n$ J.F. Principal component analysis and biochemical characterization of protein and starch reveal primary targets for improving sorghum grain. Plant Sci., 2010, 179: 598-611 (doi: 10.1016/j.plantsci.2010.08.020).

14. Grootboom A.W., Mkhonza N.L., Mbambo Z., O'Kennedy M.M., da Silva L.S., T a y lo r J., T a y lo r J.R.N., C h i k w a mba R., M e h lo L. Co-suppression of synthesis of major $\alpha$-kafirin sub-class together with $\gamma$-kafirin- 1 and $\gamma$-kafirin-2 required for substantially improved protein digestibility in transgenic sorghum. Plant Cell Rep., 2014, 33: 521537 (doi: 10.1007/s00299-013-1556-5).

15. O ria M.P., H a make r B.R., S hull J.M. Resistance of sorghum $\alpha-, \beta$ - and $\gamma$-kafirins to pepsin digestion. J. Agric. Food Chem., 1995, 43: 2148-2153.

16. D u odu K.G., T a y lo r J.R.N., B e 1 t o n P.S., H a m a k e r B.R. Factors affecting sorghum protein digestibility. $J$. Cereal Sci., 2003, 38: 117-131 (doi: 10.1016/S0733-5210(03)00016-X).

17. Saito Y., Shigemitsu T., Yamasaki R., S a sou A., Goto F., Kishida K., Kuroda M., Tanaka K., Morita S., Satoh S., Masumura T. Formation mechanism of the internal structure of type I protein bodies in rice endosperm: relationship between the localization of prolamin species and the expression of individual genes. The Plant J., 2012, 70: 1043-1055 (doi: 10.1111/j.1365-313X.2012.04947.x).

18. Takemoto Y., Coughlan S.J., Okita T.W., S atoh H., Ogawa M., Kuma $\mathrm{m}$ a ru T. The rice mutant esp2 greatly accumulates the glutelin precursor and deletes the protein disulfide isomerase. Plant Physiol., 2002, 128: 1212-1222 (doi: 10.1104/pp.010624).

19. Takaiwa F., Hirose S., Takagi H., Yang L., Wak as a Y. Deposition of a recombinant peptide in ER-derived protein bodies by retention with cysteine-rich prolamins in transgenic rice seed. Planta, 2009, 229: 1147-1158 (doi: 10.1007/s00425-009-0905-7).

20. Barro F., Rooke L., B ekes F., Gras P., T a tham A.S., Fido R., Lazzeri P.A., S h ewry P.R., B a r c e lo P. Transformation of wheat with high molecular weight subunit genes results in improved functional properties. Nat. Biotechnol., 1997, 15: 1295-1299 (doi: 10.1038/nbt1197-1295).

21. Rakszegi M., B e kes F., Lang L., Ta mas L., Shew ry P.R., B edo Z. Technological quality of transgenic wheat expressing an increased amount of a HMW glutenin subunit. J. Cereal Sci., 2005, 42: 15-23 (doi: 10.1016/j.jcs.2005.02.006). 
22. Rakszegi M., Past ori G., Jo nes H.D., B eke s F., B ut ow B. Technological quality of field grown transgenic lines of commercial wheat cultivars expressing the 1A61 HMW glutenin subunit gene. J. Cereal Sci., 2008, 47: 310-321 (doi: 10.1016/j.jcs.2007.04.010).

23. Ble chl A., Li n J., Nguyen S., Chan R., Anderson O.D., D upont F.M. Transgenic wheats with elevated levels of Dx5 and/or Dy10 high-molecular-weight glutenin subunits yield doughs with increased mixing strength and tolerance. J. Cereal Sci., 2007, 45: 172-183 (doi: 10.1016/j.jcs.2006.07.009).

24. M a s ci S., D'Ovidio R., S coss a F., Pat a c chini C., Lafiandra D. Production and characterization of a transgenic bread wheat line over-expressing a low molecular-weight glutenin subunit gene. Mol. Breed., 2003, 12(3): 209-222 (doi: 10.1023/A:1026346823301).

25. Leon E., Marin S., Gimenez M.J., Piston F., Rodriguez-Quijano M., S h e w ry P.R., B arro F. Mixing properties and dough functionality of transgenic lines of a commercial wheat cultivar expressing the 1A61, 1D65 and 1Dy10 HMW glutenin subunit genes. J. Cereal Sci., 2009, 49: 148-156 (doi: 10.1016/j.jcs.2008.08.002.).

26. He G.Y., Rooke L., Ste ele S., Bekes F., Gras P., Tatham A.S., Fido R., B a r c e lo P., Shewry P.R., Lazzeri P. Transformation of pasta wheat (Triticum turgidum L. var. durum) with high-molecular-weight glutenin subunit genes and modification of dough functionality. Mol. Breed., 1999, 5(4): 377-386 (doi: 10.1023/A:1009681321708).

27. Gadaleta A., Blechl A.E., Nguyen S., Cardone M.F., Ventura M., Quick J.S., B la n co A. Stably expressed D-genome derived HMW glutenin subunit genes transformed into different durum wheat genotypes change dough mixing properties. Mol. Breed., 2008, 22: 267-279 (doi: 10.1007/s11032-008-9172-8).

28. Tosi P., D'Ovidio R., Napie r J.A., B e kes F., Shewry P.R. Expression of epitope-tagged LMW glutenin subunits in the starchy endosperm of transgenic wheat and their incorporation into glutenin polymers. Theor. Appl. Genet., 2004, 108: 468-476 (doi: 10.1007/s00122-003-1459-x).

29. Tosi P., Masci S., Giovangrossi A., D'Ovidio R., Bekes F. Modification of the low molecular weight (LMW) glutenin composition of transgenic durum wheat: Effects on glutenin polymer size and gluten functionality. Mol. Breed., 2005, 16: 113-126 (doi: 10.1007/s11032-005-5912-1).

30. Liu X., Jin W., Liu J., Zhao H., Guo A. Transformation of wheat with the HMW-GS 1Bx14 gene without markers. Russ. J. Genet., 2011, 47(2): 182-188 (doi: 10.1134/S1022795411010066).

31. Altpeter F., V a sil V., S riva st a v a V., V a s i l I.K. Integration and expression of the high-molecular-weight glutenin subunit 1A61 gene into wheat. Nat. Biotechnol., 1996, 14: 1155-1159 (doi: 10.1038/nbt0996-1155).

32. Sangtong V., Moran L., Chikwamba R., Wang K., Woodman-Clikeman W., Long J., Le e M., S c o t t P. Expression and inheritance of the wheat Glu-1DX5 gene in transgenic maize. Theor. Appl. Genet., 2002, 105(6-7): 937-945 (doi: 10.1007/s00122-002-1036-8).

33. Kumar T., Dweikat I., Sato S., Ge Z., Nersesian N., Elthon T., Bean S., Ioe rge r B.P., Tiley M., Cle me nte T. Modulation of kernel storage proteins in grain sorghum (Sorghum bicolor (L.) Moench). Plant Biotechnol. J., 2012, 10: 533-544 (doi: 10.1111/j.1467-7652.2012.00685.x).

34. Ali N., Datta S.K., D atta K. RNA interference in designing transgenic crops. GM Crops, 2010, 1(4): 207-213 (doi: 10.4161/gmcr.1.4.13344).

35. Katoch R., Thakur N. Advances in RNA interference technology and its impact on nutritional improvement, disease and insect control in plants. Appl. Biochem. Biotechnol., 2013, 169(5): 1579-1605 (doi: 10.1007/s12010-012-0046-5).

36. Younis A., Siddique M.I., Ki m C.-K., Li m K.-B. RNA Interference (RNAi) induced gene silencing: a promising approach of hi-tech plant breeding. Int. J. Biol. Sci., 2014, 10(10): 1150-1158 (doi: 10.7150/ijbs.10452).

37. Gil-Humanes J., Piston F., Hernando A., Alvarez J.B., Shewry P.R., Barro F. Silencing of $\gamma$-gliadins by RNA interference (RNAi) in bread wheat. J. Cereal Sci., 2008, 48: 565-568 (doi: 10.1016/j.jcs.2008.03.005).

38. Gil-Humanes J., Piston F., Gimenez M.J., Martın A., Barro F. The introgression of RNAi silencing of $\gamma$-gliadins into commercial lines of bread wheat changes the mixing and technological properties of the dough. PLOS ONE, 2012, 7(9): e45937 (doi: 10.1371/journal.pone.0045937).

39. Wieser H., Koehler P., Folck A., B e cker D. Characterization of wheat with strongly reduced $\alpha$-gliadin content. $9^{\text {th }}$ Annual Gluten Workshop, 14-16 September, 2006, San Fransisco, California, USA. G.L. Lookhart, P.K.W. Ng (eds.). AACC, St Paul, MN, 2006: 13-16.

40. Altenbach S.B., Tanaka C.K., Allen P.V. Quantitative proteomic analysis of wheat grain proteins reveals differential effects of silencing of omega-5 gliadin genes in transgenic lines. J. Cereal Sci., 2014, 59: 118-125 (doi: 10.1016/j.jcs.2013.11.008).

41. Gil-Humanes J., Pistón F., Tollefsen S., Sollid L.M., B arro F. Effective shutdown in the expression of celiac disease-related wheat gliadin T-cell epitopes by RNA interference. PNAS USA, 2010, 107(39): 17023-17028 (doi: 10.1073/pnas.1007773107). 
42. Segal G., Song R., Messing J. A new opaque variant of maize by a single dominant RNA-interference-inducing transgene. Genetics, 2003, 165: 387-397.

43. Huang S., Frizzi A., Florida C.A., Kruger D.E., Luethy M.H. High lysine and high tryptophan transgenic maize resulting from the reduction of both $19-$ and $22-\mathrm{kD} \alpha$-zeins. Plant Mol. Biol., 2006, 61: 525-535 (doi: 10.1007/s11103-006-0027-6).

44. Wu Y., Messing J. RNA interference-mediated change in protein body morphology and seed opacity through loss of different zein proteins. Plant Physiol., 2010, 153: 337-347 (doi: 10.1104/pp.110.154690).

45. Wu Y., Holding D.R., Messing J. $\gamma$-Zeins are essential for endosperm modification in quality protein maize. PNAS USA, 2010, 107(29): 12810-12815 (doi: 10.1073/pnas. 1004721107).

46. Guo X., Yuan L., Chen H., S ato S.J., Clemente T.E., Holding D.R. Nonredundant function of zeins and their correct stoichiometric ratio drive protein body formation in maize endosperm. Plant Physiol., 2013, 162: 1359-1369 (doi: 10.1104/pp.113.218941).

47. Da Silva L.S., Jung R., Zhao Z.Y., Glassman K., Grootboom A.W., Mehlo L., O'Kennedy M.M., Taylor J., Taylor J.R.N. Effect of suppressing the synthesis of different kafirin sub-classes on grain endosperm texture, protein body structure and protein nutritional quality in improved sorghum lines. J. Cereal Sci., 2011, 54: 160-167 (doi: 10.1016/j.jcs.2011.04.009).

48. D a Silva L.S., Taylor J., Taylor J.R.N. Transgenic sorghum with altered kafirin synthesis: kafirin solubility, polymerization and protein digestion. J. Agric. Food Chem., 2011, 59: 9265-9270 (doi: 10.1021/jf201878p).

49. El'konin L.A., Domanina I.V., Ital'yanskaya Yu.V., Rakitin A.L., Ravi n N.V. Materialy $V$ Vserossiiskogo simpoziuma «Transgennye rasteniya: tekhnologiya sozdaniya, biologicheskie svoistva, primenenie, bezopasnost'» [Proc. V All-Russia Symp. «Transgenic plants: the creation, biological properties, usage, security»]. Moscow, 2014: 239-242.

50. Oria M.P., Hamake r B.R., Axtell J.D., Huang C.P. A highly digestible sorghum mutant cultivar exhibits a unique folded structure of endosperm protein bodies. PNAS USA, 2000, 97: 5065-5070 (doi: 10.1073/pnas.080076297).

51. Nagamine A., Matsusaka H., Ushijima T., Kawagoe Y., Ogawa M., Okit a T.W., Kumamaru T. A role for the cysteine-rich $10 \mathrm{kDa}$ prolamin in protein body I formation in rice. Plant Cell Physiol., 2011, 52(6): 1003-1016 (doi: 10.1093/pcp/pcr053).

52. Ki m H.-J., Le e J.-Y., Y o on U.-H., Lim S.H., Kim Y.-M. Effects of reduced prolamin on seed storage protein composition and the nutritional quality of rice. Int. J. Mol. Sci., 2013, 14: 17073-17084 (doi: 10.3390/ijms140817073).

53. Kawakatsu T., Hirose S., Yasuda H., Takaiwa F. Reducing rice seed storage protein accumulation leads to changes in nutrient quality and storage organelle formation. Plant Physiol., 2010, 154: 1842-1854 (doi: 10.1104/pp.110.164343).

54. Kusaba M., Miyahara K., Lida S., Fukuoka H., Takario T., Sassa H., Nishimura M., Nishio T. Low glutenin content 1: a dominant mutation that suppresses the glutenin multigene family via RNA silencing in rice. Plant Cell, 2003, 15: 1455-1467 (doi: 10.1105/tpc.011452).

55. Ufaz S., Galili G. Improving the content of essential amino acids in crop plants: goals and opportunities. Plant Physiol., 2008, 147(3): 954-961 (doi: 10.1104/pp.108.118091).

56. Falco S.C., Ke ele r S.J., Rice J.A. Chimeric genes and methods for increasing the lysine and threonine content of the seeds of plants. US Patent 5,773,691. A01H 5/00. E. I. Du Pont de Nemours and Company. Appl. No.: 474,633. Filed: Jun. 7, 1995. Date of Patent: Jun. 30, 1998.

57. Huang S., Kruger D.E., Frizzi A., D'Ordine R.L., Florida C.A., Adams W.R., B row n W.E., Lu e thy M.H. High-lysine corn produced by the combination of enhanced lysine biosynthesis and reduced zein accumulation. Plant Biotechnol. J., 2005, 3: 555-569 (doi: 10.1111/j.1467-7652.2005.00146.x).

58. Houmard N.M., Mainville J.L., Bonin C.P., Huang S., Luethy M.H., Malv a r T.M. High-lysine corn generated by endosperm-specific suppression of lysine catabolism using RNAi. Plant Biotechnol. J., 2007, 5: 605-614 (doi: 10.1111/j.1467-7652.2007.00265.x).

59. Frizzi A., Huang S., Gilbertson L.A., Armstrong T.A., Luethy M.H., Ma1var T.M. Modifying lysine biosynthesis and catabolism in corn with a single bifunctional expression/silencing transgene cassette. Plant Biotechnol. J., 2008, 6(1): 13-21 (doi: 10.1111/j.1467-7652.2007.00290.x).

60. Long X., Liu Q., Chan M., Wang Q., S un S.S.M. Metabolic engineering and profiling of rice with increased lysine. Plant Biotechnol. J., 2012, 11(4): 490-501 (doi: 10.1111/pbi.12037).

61. Huang S., Frizzi A., Florida C.A., Kruger D.E., Luethy M.H. High lysine and high tryptophan transgenic maize resulting from the reduction of both $19-$ and $22-\mathrm{kD} \alpha-z e i n s$. Plant Mol. Biol., 2006, 61: 525-535 (doi: 10.1007/s11103-006-0027-6).

62. Wong H.W., Liu Q., Sun S.S.M. Biofortification of rice with lysine using endogenous histones. Plant Mol. Biol., 2015, 87: 235-248 (doi: 10.1007/s11103-014-0272-z).

63. Yu P., Zhang Z., Zhu S., Li u A.. Seed-specific expression of the lysine-rich protein gene sb401 significantly increases both lysine and total protein content in maize seeds. Mol. Breed., 
2004, 14(1): 1-7 (doi: 10.1023/B:MOLB.0000037990.23718.d6).

64. Yue J., Li C., Zhao Q., Zhu D., Yu J. Seed-specific expression of a lysine-rich protein gene, GhLRP, from cotton significantly increases the lysine content in maize seeds. Int. J. Mol. Sci., 2014, 15(4): 350-365 (doi: 10.3390/ijms15045350).

65. Rukavtsova E.B., Lebedeva A.A., Zakharchenko N.S., Bur'yanov Ya.I. Fiziologiya rastenii, 2012, 60(1): 17-30.

66. Tuteja N., Verma S., Sahoo R.K., Raveendary S., Reddy IN B.L. Recent advances in development of marker-free transgenic plants: Regulation and biosafety concern. $J$. Biosci., 2012, 37: 167-197 (doi: 10.1007/s12038-012-9187-5).

67. De Paepe A., De Buck S., Nolf J., Van Lerberge E., Depicker A. Site-specific T-DNA integration in Arabidopsis thaliana mediated by the combined action of CRE recombinase and $\phi C 31$ integrase. Plant J., 2013, 75: 172-184 (doi: 10.1111/tpj.12202).

68. B ortesia L., Fis cher R. The CRISPR/Cas9 system for plant genome editing and beyond. Biotechnol. Adv., 2015, 33: 41-52 (doi: 10.1016/j.biotechadv.2014.12.006). 